\title{
ETHNOGRAPHY AS AN INQUIRY PROCESS IN SOCIAL SCIENCE RESEARCH Ganga Ram Gautam*
}

\begin{abstract}
This article is an attempt to present the concept of ethnography as a qualitative inquiry process in social science research. The paper begins with the introduction to ethnography followed by the discussion of ethnography both as an approach and a research method. It then illustrates how ethnographic research is carried out using various ethnographic methods that include participant observation, interviewing and collection of the documents and artifacts. Highlighting the different ways of organizing, analyzing and writing ethnographic data, the article suggests ways of writing the ethnographic research.
\end{abstract}

\section{THE INQUIRY PROCESS}

Inquiry process begins consciously and/or subconsciously along with the beginning of human life. The complex nature of our life, problems and challenges that we encounter both in personal and professional lives and the several unanswered questions around us make us think and engage in the inquiry process. Depending upon the nature of the work that one does and the circumstances around them, people choose the inquiry process that fits into their inquiry framework that is built upon the context they are engaged in. This inquiry process in education is termed as research and research in education has several dimensions. The inquiry process in education is also context dependent and it is driven by the nature of the inquiry questions that one wants to answer.

\section{UNDERSTANDING ETHNOGRAPHY}

Ethnography, as a form of qualitative research, has now emerged as one of the powerful means to study human life and social behavior across the globe.

\begin{abstract}
Over the past fifteen years there has been an upsurge of ethnographic work in British educational research, making ethnography the most commonly practiced qualitative research method. This interest in ethnography was sparked by the advent of the 'new sociology' (M.F.D. Young, 1971), which concentrated on the taken for granted categories of everyday life and the social construction of human reality (Woods, 1988, p. 88).
\end{abstract}

The last quarter of the 19th century marks the beginning of ethnography when anthropologists used the term 'ethnography' to describe the life and 
behavior of people in the rural and aboriginal communities. Etymologically, the term ethnography is a combination of the terms 'ethno' and 'graphy' which are rooted to the Greek terms 'ethnoi' meaning the 'the other' and 'graphein' that means 'to write' respectively. Originally, the term ethnography was used to refer to the writing about 'the other people' that means people who were not Greek. When it is writing about the 'other', the writing includes who these people are, what they do, how they live, how they interact in the community and several other things that are connected to their life. While studying the 'others', "Anthropologists began to use the term ethnography for descriptive accounts of the life ways of particular sets of the people who lived in colonial situations around the world" (Erickson, 2011, p. 44). The ethnographic accounts were claimed to be nearer to the truth and comprehensive enough to understand the life and behaviors of the people because ethnography, as it is connected to the anthropological route, documents the people's beliefs and practices from the people's own perspectives.

\section{DEFINING ETHNOGRAPHY}

The definition of ethnography varies from contexts to contexts. There are a number of definitions of ethnography which cover various aspects of the inquiry under the study. Some scholars see ethnography as the process of collecting information from the field whereas some see it as the outcome of the information in the form of the richness of the data and the rigor that has been maintained while doing it. How ethnography is defined also depends on the background and orientation of the researchers and the definitions of ethnography suggest a certain amount of convergence around core elements such as immersing in the field, thick descriptions and studying the culture of the people etc. while simultaneously pointing to some divergence as well in the focus. (Bryman, 2001).

Historically speaking, scholars from anthropological background seem to have focused their attention more on the cultural aspects of the people where an ethnography "was a descriptive account of a community or a culture, usually one located outside the west" (Atkinson \& Hammersley, 2007, p. 1). Some other scholars have connected ethnography more with the process of how the information is collected when it reads, "Ethnography is about telling a credible, rigorous, and authentic story. Ethnography gives voice to people in their own local context, typically relying on verbatim quotations and a "thick" description of events" (Fetterman, 2010). According to this definition, ethnography is the way of collecting information and communicating it to the readers. The information that is collected from the field has to be rich and it should include the expression of the people in their own words. The researcher 
has to be sincere enough to communicate the social realities with reference to their cultural contexts.

For Brewer, ethnography is not that easy to define as "it confronts the common-sense misrepresentations of ethnography, defending it against the allegation that it is journalism in another guise" (Brewer, 2005, p. 10). Brewer proposes two different ways of defining ethnography as 'big' and 'little' ethnography. He defines little ethnography as

\footnotetext{
the study of people in naturally occurring settings or 'fields' by means of methods which capture their social meanings and ordinary activities, involving the researcher participating directly in the setting, if not also the activities, in order to collect data in a systematic manner but without meaning being imposed on them externally and the big ethnography for him is the synonym for qualitative research as a whole, and virtually describes any approach as ethnographic that avoids surveys as the means of data collection (Brewer, 2005, p. 17).
}

This distinction shows how people perceive ethnography differently in different contexts.

Highlighting how the research is carried out, Creshwell defines ethnography as

$$
\begin{aligned}
& \text { a strategy of inquiry in which the researcher studies an intact cultural } \\
& \text { group in a natural setting over a prolonged period of time by } \\
& \text { collecting, primarily, observational and interview data (Creswell, } \\
& \text { 2007b). The research process is flexible and typically evolves } \\
& \text { contextually in response to the lived realities encountered in the field } \\
& \text { setting (Le Compte and Schensul, 1999), (Creshwell, 2009, p. 30). }
\end{aligned}
$$

This definition focuses the role of observation and the interaction between the researcher and the participants in the field while doing the ethnographic research. Ethnography in this sense is a dialogical process between the researcher and researched and the collection of the responses with reference to the context of the respondents. Similar meaning can be drawn in another definition given by Yin saying that "ethnography involves a field-based study lengthy enough to surface people's everyday norms, rituals, and routines in detail" (Yin, 2011, p. 17).

Reviewing the various ethnographies from different disciplines including education, Pole and Morrison (2003) have identified the following characteristics of ethnography:

(a) A focus on a discrete location, event(s) or setting.

(b) A concern with the full range of social behavior within the location, event or setting.

(c) The use of a range of different research methods which may combine qualitative and quantitative approaches but where the emphasis is upon understanding social behavior from inside the discrete location, event or setting. 
(d) An emphasis on data and analysis which moves from detailed description to the identification of concepts and theories which are grounded in the data collected within the location, event or setting.

(e) An emphasis on rigorous or thorough research, where the complexities of the discrete event, location or setting are of greater importance than overarching trends or generalizations (Pole \& Morrison, 2003, p. 3).

The list shows that ethnography is something that documents the every single details of the phenomenon that is under study and the information is collected through multiple channels. The rich information is then looked upon with great care before any explanation is made so that the conclusion generated from the information reflects the voice of the people who were included under the study. The definition below presents the summary of what ethnography is about in the research context.

Ethnography is a research strategy that allows researchers to explore
and examine the cultures and societies that are a fundamental part of
the human experience. Unlike many other scientific research strategies,
the ethnographer as researcher is not typically a detached or
uninvolved observer. The ethnographer collects data and gains insight
through firsthand involvement with research subjects or informants.
With few exceptions, the ethnographer conducts research by
interacting with other human beings that are part of the study; this
interaction takes many forms, from conversations and interviews to
shared ritual and emotional experiences" (Murchison, 2010, p. 4).

Thus, ethnography is the systematic study of a particular group of people or a phenomenon which helps the researcher to understand the ground realities based on the rich information collected from the field through rigorous efforts. Ethnography has been used in research for the detailed study of the phenomenon in order to have its comprehensive understanding. According to the literature, ethnography has a very wide scope and it can be used, for example (Lofland \& Lofland, 1984):

(a) to give accounts of elementary school classrooms, life in classroom, 'complexities of urban classroom'

(b) to search for meanings (cultural norms, the use of language, worldviews etc.)

(c) to look at certain behaviors and practices and 'episodes' (things such as divorce, crime, illness etc.)

(d) to understand the 'encounters' (social interaction)

(e) to examine the 'roles' (in families, organizations, relationships etc.) and 'relationships' (in groups, social circles, sports teams, etc.) 
(f) to study the organization sand 'settlements' (while, unlike anthropologists, we don't study entire societies, we are often interested in finding out how certain subsets or segments of it work)

\section{TYPE OF ETHNOGRAPHY}

Ethnography is a very big subject. The literature now talks about different types of ethnographies and all of them have developed as disciplines on their own right. As it is not possible to discuss them all in detail and this is not the main purpose of the article, I would only like to mention the list of different ethnographies that I have surveyed in the literature.

(a) Applied ethnography- contributions to policy and practice

(b) Auto-ethnography- study of oneself

(c) Big ethnography- a perspective or a particular approach to qualitative research

(d) Classic realist ethnography- conventional ethnography

(e) Constitutive ethnography- social structures are social accomplishments (Mehan, 1978, p. 36) or ethnography of practice

(f) Critical ethnography- the researcher not only studies and understands society, but also critiques and potentially changes the society through his or her work.

(g) Feminist ethnography- observational research conducted over time and motivated by a commitment to women. Social scientists use feminist ethnography to uncover how gender operates within different societies (Aune, 2008).

(h) Integrative/combinative ethnography: following the anthropological tradition, this constructs units of collective belonging for individual. (Baszanger \& Dodier, 2003, p. 9)

(i) Narrative ethnography- complex and overlapping contexts of the storying process

(j) Naturalistic ethnography- ethnographer remains careful not to disturb the ecology of [the participants'] social world by introducing [her] own subjectivity, beliefs, or interest (Yin, 2011, p. 12)

(k) Performance ethnography- staged re-enactment of ethnographically derived notes (Alexander, 2005, p. 411)

(1) Realist ethnography- the researchers gives the object account, normally in the third person

(m) Reflexive ethnography- confessional, theoretical, textual, and deconstructive (Cultural Marxist's standpoint) (Foley, 2002)

(n) Small ethnography - as a field work i.e. doing ethnography 
(o) Subversive ethnography- ethnographies of specific sexual world that challenge assumption (Denzin \& Lincoln, 2005, p. 366)

(p) Virtual ethnography- the data may be restricted entirely to what can be downloaded from the internet. (Markham 1998, 2005; Hine 2000)

\section{ETHNOGRAPHY AS AN APPROACH}

Ethnography is grounded to the ontological assumption that there are multiple realities that exist in the community and people perceive them in their own ways. The epistemological considerations of ethnography suggest that the construction of knowledge in society is interdependent to the interaction between the individuals and the society at large. People construct and deconstruct knowledge in their everyday life and

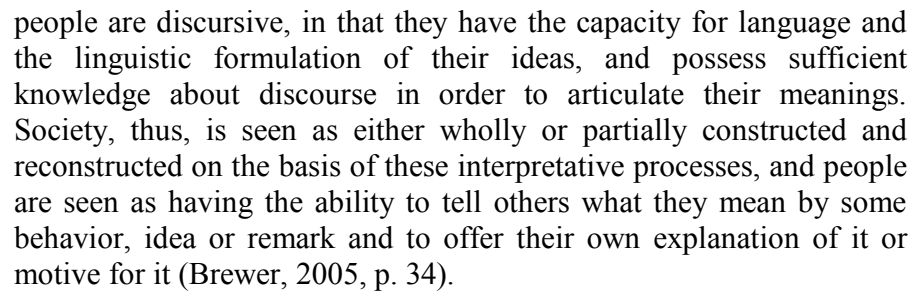

In this context, ethnography is the approach that tells us how people understand the world, how they describe it and how they communicate it to others. Here the researcher is someone who brings the cultural perspectives of people and interpretations of the world within the social milieu they live in.

Society is very complex and there are cultures within the culture. There are groups within groups and there are subgroups. There are layers after layers. There are various ideologies that govern the understanding of people. There are people with various socio-economic background.

These elements of culture operate unnoticed in day-to-day situationsmuch as grammar operates in language. Different subgroups in a culture may have widely disparate attitudes about the surface level of their kinship, religious, and economic systems, but they generally share a common belief in the deeper, often subconscious meaning behind these culture elements (Fetterman, 2010, p. 17).

These societal complexities and variations influence how people interpret the world. Thus, ethnography aims to cultural interpretations of all these intricacies that prevail in the society with reference to the people's understanding about the world. The ethnographer is, thus, required to have the ability to understand the culture of the community from the perspectives of people and interpret it in their own term.

Ethnography as an approach has the following attributes (Whitehead, 2004):

(1) Ethnography includes both qualitative and quantitative methods, and both classical and non-classical ethnographic approaches. 
(2) Ethnography is more than simply methods, but has ontological and epistemological properties.

(3) Ethnography is a holistic approach to the study of cultural systems.

(4) Ethnography is the study of the socio-cultural contexts, processes, and meanings within cultural systems.

(5) Ethnography is the study of cultural systems from both emic and etic perspectives.

(6) Ethnography is greatly dependent on fieldwork.

(7) Ethnography is a process of discovery, making inferences, and continuing inquiries in an attempt to achieve emicvalidity.

(8) Ethnography is an iterative process of learning episodes.

(9) Ethnography is an open-ended emergent learning process, and not a rigid investigator controlled experiment.

(10) Ethnography is a highly flexible and creative process.

(11) Ethnography is an interpretive, reflexive, and constructivist process.

(12) Ethnography requires the daily and continuous recording of fieldnotes.

(13) Ethnography may be carried out by individual investigators, or by teams of investigators.

(14) Ethnography presents the world of its host population in human contexts of thickly described case studies.

\section{ETHNOGRAPHY AS A RESEARCH METHOD}

Ethnography as a research method offers the researcher an opportunity to collect information from the field in a great deal of varieties. Ethnography encompasses the idea that information is embedded in the socio-cultural activities of the society and understanding the meaning of information is possible only when the researcher is immersed in the field. Therefore, ethnographer has to be aware of the three key principles of ethnography viz. naturalism, understanding and discovery (Genzuk, 2003) and then find the appropriate ways of collecting the information. Here, naturalism refers to the collection of information from the participants through first-hand context in a natural setting

not by inferences from what people do in artificial settings like experiments or from what they say in interviews about what they do elsewhere ... social events and processes must be explained in terms of their relationship to the context in which they occur (Genzuk, 2003). 
Understanding refers to the familiarity of the cultural perspectives of the participants and discovery means ethnographic research should be flexible to accommodate the emergence of the phenomenon as the research continues inductively. In order to be methodic in ethnographic research, (Genzuk, 2003) recommends the researcher to internalize the following features of ethnographic work and find ways of collecting information from various sources so that the interpretation can be made both from the participants' perspectives and the outsiders' perspectives:

(1) People's actions and accounts are studied in everyday contexts, rather than under conditions created by the researcher - such as in experimental setups or in highly structured interview situations. In other words, research takes place 'in the field'.

(2) Data are gathered from a range of sources, including documentary evidence of various kinds, but participant observation and/or relatively informal conversations are usually the main ones.

(3) Data collection is, for the most part, relatively 'unstructured', in two senses. First, it does not involve following through a fixed and detailed research design specified at the start. Second, the categories that are used for interpreting what people say or do are not built into the data collection process through the use of observation schedules or questionnaires. Instead, they are generated out of the process of data analysis.

(4) The focus is usually on a few cases, generally fairly small-scale, perhaps a single setting or group of people. This is to facilitate indepth study.

(5) The analysis of data involves interpretation of the meanings, functions, and consequences of human actions and institutional practices, and how these are implicated in local, and perhaps also wider, contexts. What are produced, for the most part, are verbal descriptions, explanations, and theories; quantification and statistical analysis play a subordinate role at most.(M. Hammersley, 1990 cited in Genzuk, 2003)

\section{ETHNOGRAPHY IN ACTION: FIELD WORK}

Ethnographic field work expects the researcher's prolonged engagement in the field and immersed in the local context so that the community accepts the researcher as a member of the group. This acceptance leads to the trust and the members will then share their true stories with the researcher. The responses to the questions will be natural and authentic. It is, therefore, very important for the researchers to build a good rapport and find ways of gaining easy and comfortable access to the community under study. This can be done either by visiting the 
community several times and engaging in the informal conversation with them or by participating in the community activities and assisting them in accomplishing their community tasks as their helping hand. Once the access is granted, the researcher should try to mingle with the group and collect the data/information in a way that the researcher's activities do not sound alien. The researcher might need some time to acclimatize in the local setting and understand how things work there.

Ethnography literature mentions different methods of collecting information in ethnographic research. Some of the key methods which are paramount to ethnographic research include;

(a) Participant observation

(b) Non-participant observation

(c) Unstructured interview

(d) Collection and analysis of documents and artifacts

\section{Participant-observation}

In participant observation, the researcher joins the community as a member of the group and lives with them for a certain period of time. Participant observation is, thus, "an omnibus field strategy in that it

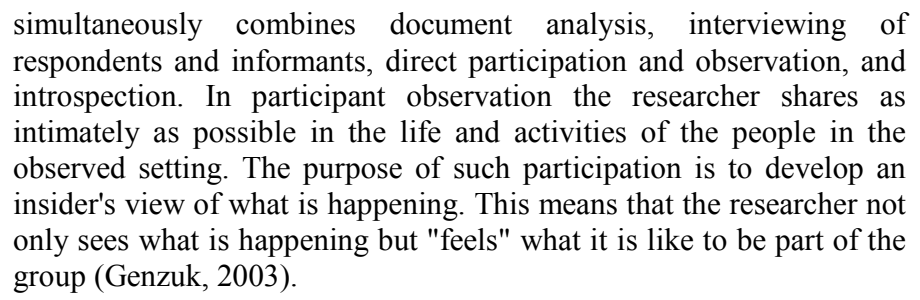

The researcher participates in the community events, engages in the conversations as an insider and shares the life of the group. For example, if you are conducting a research on the community participation in the school activities, the researcher lives in a host family in the community and perhaps joins the school as a volunteer and then participates in all school activities. As a member of the community, the researcher is now in a position to bring the insider's perspectives in the research by integrating and assimilating with them in the local culture. "Participant - observation makes ethnographic research unique and opens avenues to important types of information hard to obtain or access otherwise" (Murchison, 2010, p. 41). In addition to this, there is a sense of trust and attitude of mutual support between the participant and the researcher when the researcher joins the community as a member.

By engaging in the activities of the community the researcher takes notes of what $\mathrm{s}$ /he observes and keep record of all the details of the conversation not only between the researcher and community people but also the communication and conversation among the community members. It is 
essential that the information collected is rich and thick. All important details need to be included in the description. Stories of people, narrations of the members, anecdotes of the participants and the conversational discourse could serve as the data for the researcher in this method.

\section{Non-participant observation}

In this case, the researcher still studies the group in an in-depth manner but not sharing the life of the group but as an outsider or as a researcher. The researcher goes to the group on a regular basis, observes the behaviors of the group closely and keeps record of all the events that happens in the field. In this method,

The observation process is a three-stage funnel, according to James Spradley, beginning with descriptive observation, in which researchers carry out broad scope observation to get an overview of the setting, moving to focused observation, in which they start to pay attention to a narrower portion of the activities that most interest them, and then selected observation, in which they investigate relations among the elements they have selected as being of greatest interest. Observation should end when theoretical saturation is reached, which occurs when further observations begin to add little or nothing to researchers' understanding. This usually takes a period of days or months, but, depending on the phenomenon in question, sometimes several years (Liu \& Maitlis, 2010, pp. 610-612).

This kind of observation is often used when participant observation is not possible or undesirable for some reasons. Under certain circumstances, for example, if someone wants to carry out research on the kind of language used in public demonstrations and agitation, it might be risky or there could be a security threat for the researcher to participate as an agitator. In this context, the researcher can watch the agitation from the side very closely and keep the records of what is going on there. Similarly, if a research is conducted to look at the interaction patterns among the young children in the playground, it might not be desirable for the adult researcher to play with the children on the ground.

\section{Unstructured interviews}

The observation alone may not give a complete picture of the phenomenon under the study. As mentioned earlier that human behaviors are very complex and culturally embedded in the various tiers, it is sometimes difficult for the researcher to understand certain behaviors and events in the community just through observations. In such cases, unstructured interviews will be useful to clarify the matters and understand the true picture.

Talking to and listening to informants are key parts of the ethnographic process. In these exchanges between ethnographers and informants, the ethnographer has the chance to gain explicit knowledge (that is, to be taught directly) and to ask for clarification or follow up on things 
observed or explained previously. Through conversation and interviews, you can obtain detailed explanations and rationales as well as background information that help you make sense out of other pieces of information that may lack context. Since one of the primary goals of ethnography is to access insiders ' perspectives, interviews and conversations that allow you to record the thoughts and words of informants are absolutely essential. Therefore, you should plan carefully to utilize interviews as a research method to its maximum effect (Murchison, 2010, pp. 43-44) .

The interview takes place in the natural context as a friendly conversation and the questions might be about what they are doing, why they are doing and how they are doing.

\section{Documents, visuals and artifacts}

True culture of a particular group of people in the community is reflected through the visual media that include posters, photographs, films, documentaries, books, educational materials, community meeting minutes, emails, public notices, written manuals, wall paintings, hoarding boards, advertisement, memos, public announcement etc. These materials are very rich in describing the cultural practices and they help researchers to make sense of what was observed in the community. Therefore, in ethnographic research, it is important to collect these materials as they are and include them in the data.

\footnotetext{
Recently ethnographers have become more interested in collecting the visual representations that their informants produce. In this case, these drawings, pictures, or diagrams become cultural objects that the ethnographer can examine and analyze. Ethnographers have asked their informants to draw pictures reflecting certain ideas or moments, to take pictures, or even to keep journals. These exercises have placed more direct control of the research process in the hands of informants by making them directly responsible for producing the data that are collected (Murchison, 2010, p. 47).
}

If such documents are not available for distribution, digital picture of them will still serve the purpose. In addition to this, the researchers themselves can take the pictures of community events and film some of the activities.

\section{ETHNOGRAPHY IN THE DATA}

We have looked at the various methods of collecting the information or the data in ethnographic research. It is important that all or most of the methods described above might be essential to collect rich information from the field. Otherwise, it will be very difficult to analyze the data and identify the patterns of convergence and uniqueness of the divergence in them. "Given that every ethnography is unique, the precise nature of what may be achieved will vary, in so far as it will reflect the particular circumstances of the discrete location, event or setting within which it is conducted. Nevertheless, in general terms we would hope that 
ethnography date would achieve the following (Pole \& Morrison, 2003, pp. 3-4):

- The collection of detailed data, which would facilitate careful analysis.

- A comprehensive and contextualized description of the social action within the location, event or setting. Such descriptions are often described as rich, or thick (Geertz 1973).

- $\quad$ The portrayal of an insider's perspective, in which the meaning of the social action for the actors themselves is paramount and takes precedence over, but does not ignore, that of the researcher.

- The construction of an account of the discrete location, event or setting which is grounded in the collected data and which incorporates a conceptual framework that facilitates understanding of social action at both an empirical and theoretical level.

This shows that the information has to be very rich, thick and comprehensive. The researcher has to mention the participants' perspectives both as an insider what we call emic perspective as well his/her own interpretation as an outside what we call the etic perspective. While collecting the data, the ethnographer needs to be vigilant to observe the dynamics of the phenomenon under study and attention should be paid to document not only the regular events but also unique cases that might emerge in the field.

\begin{abstract}
A good ethnographer recognizes that there are patterns of behavior, shared sets of symbols, and structures that shape possibilities, but she also recognizes individual interests and idiosyncrasies, the role of creativity and improvisation, conflict, and the ways that social position can produce and reflect significant variety in the group. Therefore, you should plan to deal with both the regular and the extraordinary dimensions of your topic (Murchison, 2010, p. 95)
\end{abstract}

\title{
ETHNOGRAPHY WRITING
}

There are ethical issues involved in ethnographic writing and, thus, due care should be given to protect the identity rights of the participants. Ethnographic data consist of the detailed information of the participants and writing it as it is with their explicit identification might offend the participants particularly when the topic is very serious. Thus, before you approach, you need to make a decision on how you would like to proceed with your writing. There are different ways of writing ethnography. The figure below presents a continuum of ethnographic writing (Humphreys \& Watson, 2009, p. 42).

The continuum in the figure provides us the choices to write the ethnographic writing. The first in the list is called the plain ethnography. One can choose to write the information either in plain language in 
descriptive form to outline what you witnessed in the field. This is the conventional form of writing in which you as a researcher do not have much flexibility to manipulate the language that you can use in writing. This kind of writing is easy to understand and it is a straightforward account of what you have investigated in the field.

Another form of writing in the continuum is the enhanced ethnography in which there is

an account of events occurring within the investigation of a single case
which uses the presentational techniques of the novelist: descriptive
scene-setting; use of dialogues; author as a character in the narrative;
inclusion of emotional responses by author and subjects; attention to
the perspectives and stories of subjects You can report the events
(Humphreys \& Watson, 2009, p. 43).

Rather than simply describing the events as they are in the field, this kind of writing makes use of the author's creativity to write the events in such a way that readers feel like reading a novel and the characters are talking about themselves in the writing. The researcher in this writing becomes of a part of the writing process and the researcher is visible while reading it.

The third kind of writing is called the semi-fictionalized writing in

Table 2.1 Four ideal type forms of ethnographic writing, located on a continuurn from minimum to maximum manipulation of research 'materials'

\begin{tabular}{|c|c|c|c|}
\hline $\begin{array}{l}\text { A. Plain } \\
\text { Ethnography }\end{array}$ & $\begin{array}{l}\text { B. Enhanoed } \\
\text { Ethnography }\end{array}$ & $\begin{array}{l}\text { C. Semi-fictionalized } \\
\text { Ethnography }\end{array}$ & $\begin{array}{l}\text { D. Fietionallized } \\
\text { Ethnoggraphy }\end{array}$ \\
\hline $\begin{array}{l}\text { A traditional sccial } \\
\text { ocience socount of } \\
\text { events socurring } \\
\text { within the imvertigation } \\
\text { of a single case }\end{array}$ & $\begin{array}{l}\text { An account of events } \\
\text { cocurring within the } \\
\text { imvestigation of a } \\
\text { single cese which } \\
\text { uses the } \\
\text { presentational } \\
\text { techniques of the } \\
\text { novelist descriptive } \\
\text { scene-setting; use of } \\
\text { dialogues; author as a } \\
\text { character in the } \\
\text { narrative; holusion of } \\
\text { emotional responses } \\
\text { by author and } \\
\text { subjects; attention to } \\
\text { the perspectives and } \\
\text { stories of subjects }\end{array}$ & $\begin{array}{l}\text { A reatructuring of } \\
\text { events occurring } \\
\text { within one or more } \\
\text { ethnographic } \\
\text { investigations into a } \\
\text { single narrative } \\
\text { (incorporating B form } \\
\text { feesturee) } \\
\text { This la an invaluable } \\
\text { of using reseearch } \\
\text { 'data' that is highly } \\
\text { sensitive or } \\
\text { confidential and which } \\
\text { would not be } \\
\text { publishable without } \\
\text { very heary disguising }\end{array}$ & $\begin{array}{l}\text { A drawing on } \\
\text { othnographic and } \\
\text { related experiences } \\
\text { from the author's life } \\
\text { to construct an } \\
\text { entertaining and } \\
\text { edilying narrative } \\
\text { (inoorporating B } \\
\text { and C form feetures). } \\
\text { Chearacters and } \\
\text { events may be } \\
\text { "created' out of } \\
\text { materials gathered } \\
\text { over the authors } \\
\text { personal and } \\
\text { scientific lite }\end{array}$ \\
\hline $\begin{array}{l}\text { Theory: the } \\
\text { investigation and the } \\
\text { writing are informed } \\
\text { by theory and } \\
\text { contriluutions to } \\
\text { existing theory are } \\
\text { drawn out in the } \\
\text { written acoourt }\end{array}$ & Theory as A & Theory: as A & $\begin{array}{l}\text { Theory: the witing } \\
\text { is informed by social } \\
\text { soionce theories but } \\
\text { may not deal with } \\
\text { these explicitly } \\
\text { accourt }\end{array}$ \\
\hline $\begin{array}{l}\text { Truth claims mainly } \\
\text { in corrospondence } \\
\text { terms: this is as } \\
\text { close as I can get to a } \\
\text { straight 'witness- } \\
\text { statement" report of } \\
\text { wha happened' }\end{array}$ & $\begin{array}{l}\text { Truth claims mainly } \\
\text { in correspondence } \\
\text { terms: "this is } \\
\text { more-or-bes what } \\
\text { happened, but as a } \\
\text { novelist might report it' }\end{array}$ & $\begin{array}{l}\text { Truth claims mainly } \\
\text { in pragmatist terms: } \\
\text { this acoount is truer } \\
\text { than other accounts to } \\
\text { the extent to which it } \\
\text { better informs human } \\
\text { practices than do } \\
\text { those other acoounts' }\end{array}$ & Truth: as C \\
\hline $\begin{array}{l}\text { See Erntering the } \\
\text { faculty (p. } 44-5 \text { ) }\end{array}$ & $\begin{array}{l}\text { See Crossing the } \\
\text { bridge (p. } 46-7)\end{array}$ & $\begin{array}{l}\text { See Charity begins } \\
\text { at home (p. } 49-50 \text { ) }\end{array}$ & $\begin{array}{l}\text { See Serimshew } \\
\text { sorimshanks (p. 52) }\end{array}$ \\
\hline Minimum 'ma: & nipulation" & \multicolumn{2}{|c|}{ Meximum 'menipulation' } \\
\hline
\end{tabular}


which "A restructuring of events occurring within one or more ethnographic investigations into a single narrative" (Humphreys \& Watson, 2009, p. 43). The researcher combines the series of events into a single narrative to communicate the message through his or her own voices. When a research is carried out in a very sensitive topic, due care should be given not to give readers a trace of the participants' introductionin order to protect their identity. In such a case, the researcher communicates the message in a disguising manner so that the information is best communicated without exposing the participants to the audience.

Finally, another form of writing which is equally popular in ethnographic writing is the fictionalized ethnography in which

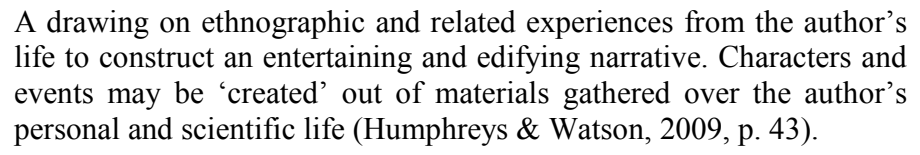

In this kind of writing, the researcher creates the fictional characters as in the fiction and the events are communicated through them. The readers cannot trace who the participants are but they get the message as they read the text. Since the writing is fictional the researcher uses the liberty of manipulating the language in order to get through the message but without distorting the intended meaning of the participants. The researcher observes the phenomenon and its events, situations, happenings etc. and the message is communicated through the character's life. This is a kind of story writing based on the information observed and collected in the field work.

Whatever you choose in ethnographic writing, one thing that must be ensured is that the writing must reflect the actual message of the participants in their own term with reference to their socio-cultural setting. The writing should depict the social reality along with the observation of the researcher both as an insider and an outsider.

\section{ETHNOGRAPHY IN ANALYSIS AND WRITING}

Ethnographic data is massive because it has to be thick and rich. Thus, analyzing the data in ethnographic research is very challenging if the researcher does not give due care while managing the data. The information collected from the field goes to the word processing and the thick description is created during the data collection process. The information should be read and re-read many times in order to see if everything that has been collected makes sense and it is meaningful. If there are any confusions, they need to be clarified by reflecting on the experience, looking at the notes taken during the observation and/or going back to the field and confirming it with the participants if there is a need. 
about just skimming the surface looking for examples or quotes. Your most significant insights will be rooted deep in the ethnographic research you have done (Murchison, 2010, p. 174).

Therefore, every details must be read with due care and attention to make sure that a complete picture is drawn. When you read the data, have your research question(s) in your mind and highlight the sections that are relevant to each research questions giving them some signs or codes. This will help you organize the data for your analysis.

While you are in the process of looking at the data, you can order the information in various ways. Maybe in the beginning, it might be confusing where to start in the massive data set but as you read them, you can make some sense and find out some patterns in them. Among several things in the data, you can order them through the:

- $\quad$ focusing and refocusing of research aims and questions,

- formal phasing of your research to address specific issues with specific people,

- $\quad$ methods used and the kinds of data they help you to construct,

- individuals and groups you chose to try to involve in your research,

- $\quad$ issues you jotted down on your interview checklists,

- ways your participants and others took photos, wrote accounts, and told stories and

- ways you tried to make sense of research experiences in your research diary notes (Crang \& Cook, 2007, pp. 132-133).

The next step after ordering the complete data and making sense of them will be to identify the key themes and patterns in the data with reference to the inquiry question and/or the research questions that you proposed to answer in your research proposal.

\footnotetext{
Ethnographers see patterns of thought and action repeat in various situations and with various players. Looking for patterns is a form of analysis. The ethnographer begins with a mass of un differentiated ideas and behaviors, and then collects pieces of information, comparing, contrasting, and sorting gross categories and minutiae until a discernible thought or behavior becomes identifiable (Fetterman, 2010, p. 97).
}

Based on the information that you have highlighted for each research questions, compile the relevant information together and look at the information with your fresh eyes. Read the information several times and try to identify some patterns in them. You can then organize the information creating appropriate themes and sub-themes with reference to the research questions in mind.

The themes that become such an important part of formal analysis usually start their lives in the data as it's constructed, then get scribbled on the margins of the data, and on separate pieces of paper, 
as it's formally analyzed and can eventually appear in the headings and subheadings of any analysis chapter(s) (Crang \& Cook, 2007, p. 133).

The themes will help you divide the analysis into chapters and subchapters or into various sections. While reading your data during this phase, you might realize that you have too much of data and you might even not need it when you will write your research report. At times you will also feel that you have missed some information that you would like to include in your research report. Thus, the advantage of having themes and sub-themes in the analysis stage is that this experience will tell you how rigorous your field work was and whether you have a complete information to respond to the themes/sub-themes that you have identified. Sometimes, you might need to go back to the field again and collect further data in order to substantiate the arguments that you raised in your analysis.

When you organize the data according to themes and/or subthemes, now you need to analyze them to go into your writing. This can be done manually or there are software packages you can use from the literature. There are some specialized software packages that you can use to analyze the qualitative data. It is your decision to choose how you are going to analyze the information based on your competence in doing it. If you choose to use software, here is a list of some of them (Imanuel, 2015):

(1) QDA Miner Lite

(2) ATLAS.ti

(3) Hyper RESEARCH

(4) MAXQDA

(5) NVivo

(6) Xsight

(7) Annotations

(8) Saturate

(9) Coding Analysis Toolkit (CAT)

(10) Computer Aided Textual markup \& Analysis (CATMA)

(11) Aquad

(12) Compendium

(13) Cassandre

(14) LibreQDA

(15) RQDA

(16) TAMS Analyzer

(17) ELAN

(18) FreeQDA

(19) Weft QDA

(20) Qiqqa

(21) QCAmap

Source: http://www.predictiveanalyticstoday.com/top-qualitative-dataanalysis-software/ 
Some of these software are free whereas some you might need to purchase them for your use. Or the organization where you work might have already purchased them for your use. You might want to check this before you decide which software you are going to use for your analysis.

Analyzing qualitative data is a time taking process. You need to have patience and you need to go a lot of back-and-forth during the process. You need to read, re-read, make sense of it with relation to the research question and the field work and revise it if necessary. To make sure that your analysis is 'truthful', Baxter and Eyles (1997) in Crang and Cook (2007) suggest adapting ideas from Lincoln and Guba so that we assess the:

- $\quad$ credibility of the account (i.e. authenticated representation of what actually occurred),

- transferability of the material (i.e. making what occurred intelligible to the audience),

- dependability of the interpretation (i.e. that it is not illogical, or how partisan it is) and

- $\quad$ confirmability of the study (i.e. the ability to audit the process that made it through personal reflection, audit processes or opportunities for informants to reply).

Your writing now gives you the answer of research questions with reference to the themes and sub-themes or topics/sub-topics whatever you choose. Synthesize the information that you have collected from various sources and try to depict the various aspects of the phenomenon under study through your writing.

\section{ETHNOGRAPHY AND REFLEXIVITY} Reflexivity is

Reflexivity is extremely important in ethnographic research.

$$
\begin{aligned}
& \text { a process by which ethnographers reveal their self-perceptions, } \\
& \text { methodological setbacks, and mental states, often includes broad general } \\
& \text { critiques of the field. Reflexivity enables ethnographers to see their } \\
& \text { research within historical and structural constraints that result from } \\
& \text { asymmetrical power distributions. (Heath, Street, \& Mills, 2008, p. 123) }
\end{aligned}
$$

Reflexivity is important in every stage of the ethnographic research. ethnographer needs to contemplate every day and look back to what has been done in terms of getting the information or data and assess how things were done. Based on the reflective observations, things should be planned for the future. Reflection in action and reflection on action are the kind of regular process in ethnographic research. Highlighting the role of reflexivity in ethnographic research Foley "argues that reflexive epistemological and narrative practices will make ethnography a more engaging, useful, public storytelling genre" ( (Foley, 2002, p. 469)). According to Foley, there are four types of reflexivity viz. confessional, theoretical, textual, and deconstructive. 


\section{ASSESSMENT/CRITICISMS OF ETHNOGRAPHY}

Ethnography has been widely used in social science research and it is a powerful research in order to understand the phenomenon in-depth and it gives you the comprehensive picture of the subject under study. Ethnography deconstructs the reality and unpacks everything transparently. Through the rigorous process of interacting with the participants on the ground and bringing the emic perspectives things are brought into the table in a more visible form. However, there are certain criticism against ethnography as an inquiry process and Brewer (2005) outlines some of them as the critiques of ethnography.

One of the main criticisms comes from the natural science perspective (empiricism) that says that ethnographic research is something that is below the standard of science because it does not follow the 'scientific' parameters of research. The critics are of the opinion that ethnography is a subjective collection of the information from the field and the findings are simply the subjective interpretations of the researcher as everything communicated to the reader is collected by the researcher based his/her subject observations in the field. There was no use of any objective observation checklists or any other 'scientific' arguments. They say that this kind of research fall into the trap of the researcher's bias and thus cannot be called the 'scientific' research. "For though ethnographic methodology has undoubtedly been made more rigorous (see Hammersley and Atkinson, 1983), it is very difficult for researchers not to indulge in selective perception" (Woods, 1988, p. 100).

Another criticism comes from the postmodern perspective.

The postmodern critique presents four chief problems for ethnography, attacking its representation of the field, the value it places on 'thick description', the reliability and validity of its data and the construction of the ethnographic text (Brewer, 2005, p. 25).

Critiques also say that ethnographic research is something like melting into the air and dissolving into nothingness (p. 19) because it does not help readers to draw any concrete conclusions. Ethnographic research just compiles the massive information and the discussion does not lead to any concluding statement. The data is so huge that there are issues with their verification and authentication.

People also say that ethnographic research has short shelf-life meaning "that the report is not a life-like image at all, but a snapshot frozen in time" (Woods, 1988, p. 100) .Other general criticisms are about the length, generalizability and replicability what is often referred to as triple crisis. Ethnographic research is very long and time consuming. Since the sample size is too small and the field of study is chosen purposively, it is neither possible to generalize nor to replicate. "To what degree can ethnographic accounts legitimately claim to represent an independent social reality?" (Hammersley, 1992, p. 2). 


\section{CONCLUSION}

Ethnographic research has been in use extensively in social science and educational research and its importance has been well recognized by the academic community. Ethnographic research, if done properly, is enlightening for the researcher and there is a lot of things ethnographer learns through the engagement. There is learning 'from' not simply 'about' which might require the researcher to unlearn many things suspend his/her judgments. Adopting an ethnographic perspective means

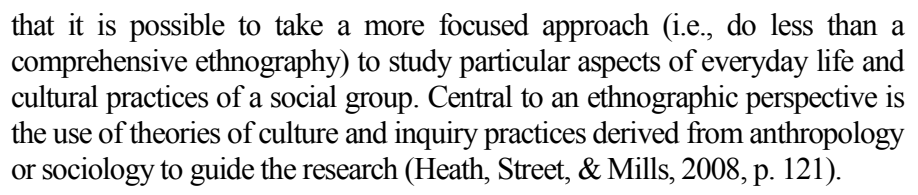

All that ethnographer needs is to be open-minded, self-motivated, and adaptable. $\mathrm{S} /$ he should be patient in the field for a long period of time. In addition to this, ethnographer must have a navigational skill to reflect on the experience and direct the inquiry process according the flow of community dynamics.

\section{WORKS CITED}

Alexander, B.K. (2005). "Performance Ethnography." In N.K. Denzin, and Y.S. Lincoln (Eds.), The SAGE Handbook of Qualitative Research. (Third ed., pp. 411-442).

Atkinson, P., and Hammersley, M. (2007). Ethnography Principles in Practice (Third ed.). London: Routledge.

Aune, K. (2008). "Feminist Ethnography." Encyclopedia of Gender and Society. London: SAGE Publications. Retrieved from Encyclopedia of gender and society: http://sageereference.com/gender/ Article_n159.html

Baszanger, I., and Dodier, N. (2003). "Ethnography Relating the Part to the Whole." In Qualitative Research Theory, Method and Practice (Second ed., pp. 9-34). London: SAGE Publications.

Brewer, J. (2005). Ethnography. Buckingham: Open University Press.

Bryman, A. (2001). Ethnography. London: SAGE.

Crang, M., and Cook, I. (2007). Doing Ethnographies. London: SAGE.

Creshwell. (2009). Research Design Qualitative, Quantitative, and Mixed Methods Approaches (Third ed.). Los Angeles: SAGE.

Denzin, N.K., and Lincoln, Y.S. (2005). The SAGE Handbook of Qualitative Research. Thousand Oaks: SAGE Publications.

Erickson, F. (2011). "A History of Qualitative Inquiry in Social and Educational Research." In N. K. Denzin, and Y.S. Lincoln, The SAGE Handbook of Qualitative Research (pp. 43 - 59). London: SAGE.

Fetterman, D.M. (2010). Ethnography Step-by-step (Third ed.). Los Angeles: SAGE. 
Foley, D. (2002). "Critical Ethnography: The Reflexive Turn." Qualitative Studies in Education, 15(5), 469-490.

Genzuk, M. (2003). A Synthesis of Ethnographic Research. Occasional Paper Series. Los Angeles, CA: Center for Multilingual, Multicultural Research, Rossier School of Education. Retrieved from http://www.bcf.usc.edu/-genzuk/Ethnographic_Research.pdf

Hammersley, M. (1992). What's Wrong with Ethnography? London: Routledge.

Heath, S.B., Street, B.V., and Mills, M. (2008). On Ethnography: Approaches to Language and Literacy Research. New York: Teachers College Press.

Humphreys, M., and Watson, T. (2009). "Ethnographic Practices: From 'Writingup Ethnographic Research' to 'Writing Ethnography'." In S. Ybema, D. Yanow, H. Wels, and F. Kamsteeg (Eds.). Organizational Ethnography Studying the Complexities of Everyday life (pp. 40-55). London: SAGE.

Imanuel. (2015, December 20). Top Qualitative Data Analysis Software. Retrieved from http://www.predictiveanalyticstoday.com/topqualitative-data-analysis-software/

Liu, F., and Maitlis, S. (2010). "Nonparticipant Observation." In A. J. Mills, G. Durepos, and E. Wiebe (Eds.), Encyclopedia of Case Study Research (pp. 610 - 612'). Thousand Oaks, CA: SAGE Publications.

Lofland, J., and Lofland, L.H. (1984). Analyzing Social Settings. Belmont, CA: Wadsworth Publishing Company, Inc.

Mehan, H. (1978). "Structuring School Structure." Harvard Educational Review, 48(1), 32-64.

Murchison, J.M. (2010). Ethnography Essentials Designing, Conducting and Presenting your Research. San Francisco: John Wiley and Sons. Inc.

Pole, C., and Morrison, M. (2003). Ethnography for Education. Berkshire: Open University Press.

Whitehead, T.L. (2004, March 27). What is Ethnography? Methodological, Ontological and Epistemological Attributes. Maryland. Retrieved from http://www.cusag.umd.edu/ documents/workingpapers/epiontattrib.pdf

Woods, P. (1988). "Educational Ethnography in Britain." In R. Sherman, and R. Webb (Eds.), Qualitative Research in Education (pp. 88107). London: Routledge.

Yin, R. K. (2011). Qualitative Research from Start to Finish. New York: The Guilford Press . 